\title{
Detection of Gamma Radiation-Induced Oxidation in Animal and Bacterial DNA
}

\author{
M Khorshed Alam* \\ Institute of Food \& Radiation Biology (IFRB), Atomic Energy Research Establishment (AERE), Ganakbari, Savar, GPO Box 3787, Dhaka 1000, \\ Bangladesh
}

[Received 26 August 2006; Accepted 07 October 2006]

\begin{abstract}
Gamma radiation-induced oxidative DNA damage, in terms of production of 8-hydroxydeoxyguanine (8-OHdG), was studied in the DNA samples from Chinese hamster ovary cell line (CHO-K1), bovine, chicken, Escherichia coli and Deinococcus radiodurans. A radiation dose response with respect to the formation of the 8-OHdG residues from the DNA molecules was observed by employing enzyme-linked immunosorbent assay (ELISA) detection system using monoclonal antibody. At high radiation doses ( $>5 \mathrm{kGy}$ ), the formation or detection of the 8-OHdG residues from bacterial DNA was declined. It was apparent that the oxidative DNA damage was dependent on the base composition of the DNA molecule. However, an inverse relation was observed between the dose limit and nitrogenous base composition especially the guanine residue. Nonetheless, DNA base composition might to be considered in cases of the radiation-induced oxidation of food or other DNA samples.
\end{abstract}

Keywords: Gamma radiation-induced oxidation, 8-Hydroxydeoxyguanine (8-OHdG), ELISA, CHO-K1, Bovine, Chicken, Escherichia coli, Deinococcus radiodurans

\section{Introduction}

The choice to examine DNA seems obvious, since DNA is a sensitive cellular target to irradiation and the changes in DNA are responsible for many effects observed in irradiated foods, such as the inactivation of microorganisms, elimination of insects, inhibition of sprouting in bulbs and tubers and delay of ripening in several fruits ${ }^{1}$. Therefore, these changes in DNA should be discernible in microbial or insect DNA or in the nucleic acids in the food itself. If DNA changes were specific to irradiation, a detection method could be designed that would have wide applicability, since most foods are derived from living organisms and obviously they contain DNA. Such a method could almost be the universal method for detecting the radiation treatment of foods. Radiation-induced changes in DNA can be analysed by a variety of analytical techniques ${ }^{1-2}$ that have mostly been employed on pure DNA or on DNA in living cells in radiation biology research. Whether or not some of these techniques can be utilized to detect irradiated food, has recently been very briefly discussed ${ }^{3-5}$. In oxic cells, the contribution of free radicals to the lethal action and DNA damage by ionising radiation amounts to around $70 \%{ }^{6-7}$. Hydroxyl radical produces a number of lesions in DNA and nucleoprotein such as base lesions, sugar lesions, single-strand breaks, double-strand breaks, abasic sites and DNA-protein cross-links by a variety of mechanisms ${ }^{4-5}$. Gamma radiation generates a lot of base products such as Fapy Guanine, 8-OHdG, 2-hydroxyadenine, 5-hydroxy cytosine, 5,6-dihydroxycytosine, 5-hydroxy uracil etc. ${ }^{5}$.

Thus, when DNA is exposed to gamma radiation, a number of chemical changes occur in the DNA molecule, e.g., change or loss of base through deamination, breakage of hydrogen bonds between strands, single or double strand breakage, cross linking with proteins and formation of hydroxy derivatives like 8-hydroxydeoxyguanosine by the oxidation of guanine base $\mathrm{s}^{5}$. Measurement of oxidized guanine base can be utilized for the detection of irradiated food, which is an important criterion for the trade of irradiated food. This study is concerned with the nature of DNA base composition for detection of gamma radiation induced oxidation.

\section{Materials and Methods \\ Subculture}

Chinese hamster (Cricetulus griseus) ovary cells (CHO-K1) were obtained from American Type Culture Collection (Rockville, MD) and routinely grown in $5 \% \mathrm{CO}_{2}$ at $37^{\circ} \mathrm{C}$ in Dulbecco's modified Eagle's medium supplemented with penicillin $(100 \mathrm{IU} / \mathrm{ml})$, streptomycin $(100 \mu \mathrm{g} / \mathrm{ml})$, and $10 \%$ foetal calf serum. During the subculture, TE buffer (containing 7.5\% Tris base and 1.8\% EDTA) was used to detach the cell from the plate surface and kept at $37^{\circ} \mathrm{C}$ for $1 \mathrm{~min}$ followed by addition of fresh medium and transferring partly to the new nutrient plate. Escherichia coli and

*Corresponding author:

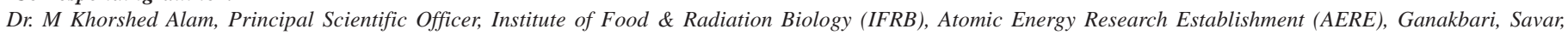
GPO Box 3787, Dhaka 1000, Bangladesh

Tel (Office): (02) 7701228; Tel (Home): (02) 8620191; Fax: +880 (02) 8613051; E-mail: alammk@hotmail.com 
Deinococcus radiodurans were grown in nutrient broth and approximate $10^{6}$ cells were taken for DNA extraction as described in the users instruction of QIAZEN kit.

\section{DNA extraction}

Total DNA extraction was carried out using QIAGEN DNeasy tissue $\mathrm{kit}^{8-10}$. RNase $(4 \mu \mathrm{lof} 100 \mathrm{mg} / \mathrm{ml}$ concentration) was added to a cell suspension of $5 \times 10^{6}$ in PBS and incubated for $2 \mathrm{~min}$ at room temperature followed by addition of $20 \mu \mathrm{l}$ proteinase-K and $200 \mu \mathrm{l}$ lysis buffer (Qiazen AL), and incubated at $70^{\circ} \mathrm{C}$ for $10 \mathrm{~min}$. Ethanol (200 $\mu \mathrm{l}$ of $99 \%)$ was added to the suspension, mixed thoroughly by vortexing. The mixture was applied to the DNeasy spin column sitting in a $2 \mathrm{ml}$ collection tube and centrifuged at $6,000 \mathrm{x} g$ for $1 \mathrm{~min}$. The flow-through was discarded and the column was placed in a new $2 \mathrm{ml}$ collection tube and washed twice with $500 \mu \mathrm{l}$ buffer AW1 and AW2 followed by centrifugation for 1 and 3 min respectively at $6000 \mathrm{x}$. In these steps the flow through was discarded. After the washing, $100 \mu \mathrm{l}$ millique water was loaded on the column and incubated for $1 \mathrm{~min}$ at room temperature followed by centrifugation at $8,000 \mathrm{x} g$ for $1 \mathrm{~min}$. The elute was collected as the purified DNA preparation. For beef and chicken, $1 \mathrm{~g}$ sample was homogenised in a mortar and pestle and $4 \mu \mathrm{l}$ RNase was added followed by the steps as described above.

\section{Determination of DNA concentration}

The concentration of DNA solutions was determined with Gene Quant (Amersham Biosciences). The concentration of $50 \mu \mathrm{g} / \mathrm{ml}$ was taken as one unit of optical absorption for double-helical DNA at $260 \mathrm{~nm}$ with optical path of $1 \mathrm{~cm}$.

\section{Enzyme-linked immunosorbent assay (ELISA)}

ABTS (2,2'-azino-di 3-ethylbenzthiazoline-6-sulfonate) substrate, monoclonal antibody (anti-mouse $\operatorname{IgG}$ ), horseradish peroxidase labelled-secondary antibody (goat anti-mouse) were purchased from Kirkegard \& Perry Laboratories, Inc (KPL), USA. Protamine sulphate was purchased from Nacalai Tesque Chemical Co Ltd, Japan. ELISA was carried out by using KPL Protein Detector ELISA kit with horseradish peroxidase (HRP), the ABTS system $^{11-13}$. The DNA samples were denatured in water bath for $10 \mathrm{~min}$ and cooled on ice for $5 \mathrm{~min}$. Aliquots of $100 \mathrm{ng}$ DNA was mixed with primary antibody (anti-mouse) and inoculated to the protamine $(1 \%)$ coated wells of immunoassay plates (Costar, USA) and incubated for $3 \mathrm{~h}$ at room temperature ${ }^{14}$, followed by washing and adding secondary antibody. The microplate was washed and the substrate solution of ABTS was incubated for $30 \mathrm{~min}$. A stop solution was mixed to stop the reaction of horseradish peroxidase, which converts ABTS, by oxidation with the heme group of HRP to produce a green coloured product. This coloured product is actually a relatively stable cationic free radical designated as ABTS ${ }^{+}$. Finally the intensity of antigen-antibody complex was measured at $405 \mathrm{~nm}$ using immuno reader (Ultrospec: Visible Plate Reader, Anthos Labtec Instruments, Austria).

\section{Results and Discussion}

Gamma radiation produces different base products like fapyguanine, 8-hydroxydeoxyguanine, 5-hydroxyhydantoin, thymine glycol, hydroxyadenine, hydroxycytosine, hydroxyuracil, etc. when DNA is exposed to radiation ${ }^{15}$. Among these oxidized base products, 8 -hydroxydeoxyguanine ( $8-\mathrm{OHdG}$ ) is the second largest ( 23 molecules $/ 10^{5}$ DNA base) in quantity ${ }^{15}$. Considering the relatively higher production of guanine oxidized base product, an attempt was made to measure the $8-\mathrm{OHdG}$ as a marker for DNA damage. A dose-response curve for the formation of $8-\mathrm{OHdG}$ in gamma irradiated-DNA of Chinese hamster cell (CHO-K1) is shown in Figure 1. The amount of the 8-OHdG formed in DNA upon gamma irradiation is linearly dependent on the dose in case of this mammalian DNA. This allows the dose-dependent formation of the 8-OHdG in gamma irradiated DNA to be used as a convenient reference standard for the detemination of the 8-OHdG. ELISA revealed that the 8-OHdG was formed in DNA on irradiation. Its accumulation in DNA depends on dose.

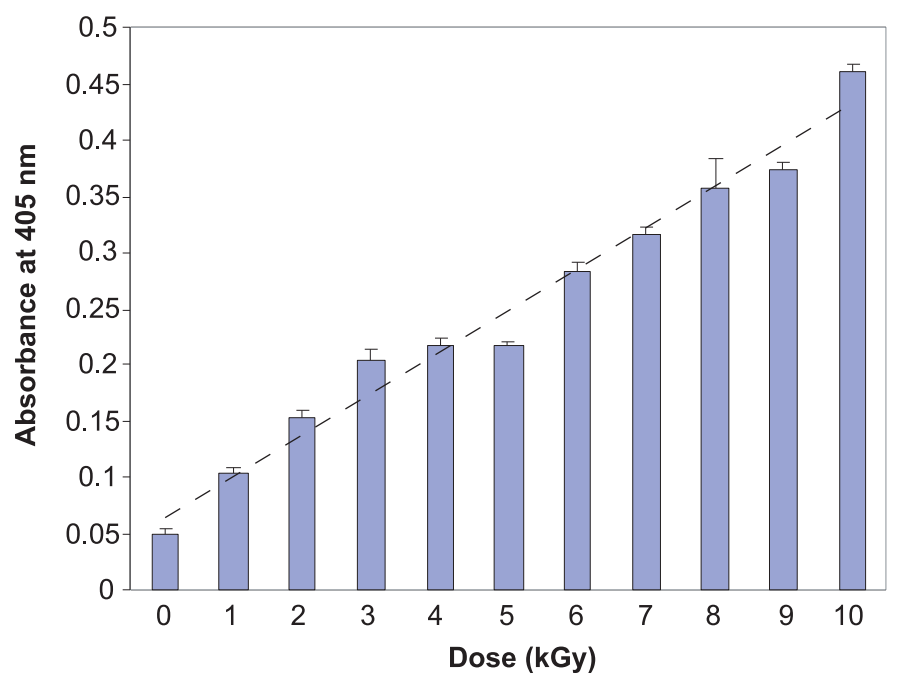

Figure 1. Detection of the 8-hydroxydeoxyguanine (8-OHdG) in irradiated-DNA of Chinese hamster ovary cell line (CHOK1) using monoclonal antibody.

Figure 2 shows the production of the 8-OHdG in the bacterial (Deinococcus radiodurans) DNA at different doses of gamma radiation. It was found that the amount of $8-\mathrm{OHdG}$ increased with the increase of radiation from 0 to $5 \mathrm{kGy}$ and, thereafter, it declined gradually with the increase of radiation dose. These results are contradictory with the DNA of CHO-K1 cell line (Figure 1). The G-C content of CHO-K1 cell line content is about $30 \%$ whereas that of Deinococcus radiodurans DNA is about $70 \%{ }^{16}$. With the higher G-C content, the production of the 8-OHdG is higher in the DNA. But the higher production of the $8-\mathrm{OHdG}$ may change the native structure of the DNA that presumably makes it more vulnerable for strand breakage due to the chain reaction of radiation. 


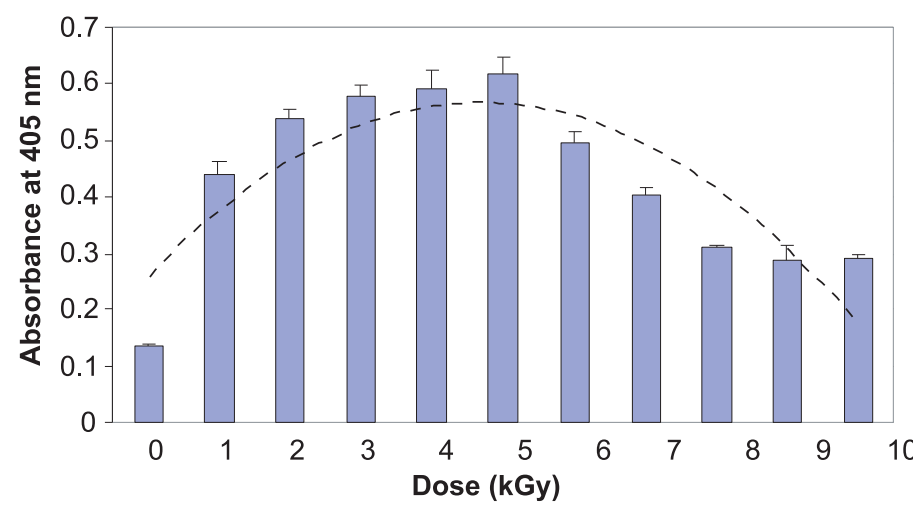

Figure 2. Detection of the 8-hydroxydeoxyguanine (8-OHdG) in irradiated-DNA of Deinococcus radiodurans using monoclonal antibody.

It is also observed that in case of animal cells like CHO-K1, bovine and chicken, the 8-OHdG could be detectable up to $12 \mathrm{kGy}$ of the radiation dose (Figure 3). But the maximum doses for the 8-OHdG detection in E. coli and D. radiodurans were 6 and $5 \mathrm{kGy}$ respectively. The GC content of CHO-K1, bovine and chicken is about $30 \%$, whereas that of $E$. coli and $D$. radiodurans is 51 and $70 \%$ respectively ${ }^{16}$. This clearly indicates that when GC content of DNA increases, the maximum dose for the 8-OHdG detection decreases. Figure 4 shows the inverse relation between the GC content and the dose limit for the detection of gamma radiationinduced oxidation.

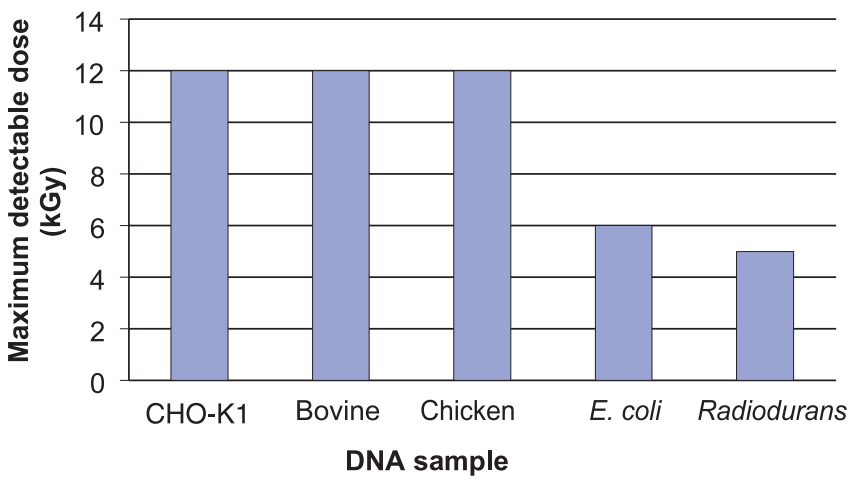

Figure 3. Detection of gamma radiation-induced DNA damage (8-hydroxydeoxyguanine) in DNA samples from various sources. $\mathrm{CHO}-\mathrm{K} 1=$ Chinese hamster ovary cell line

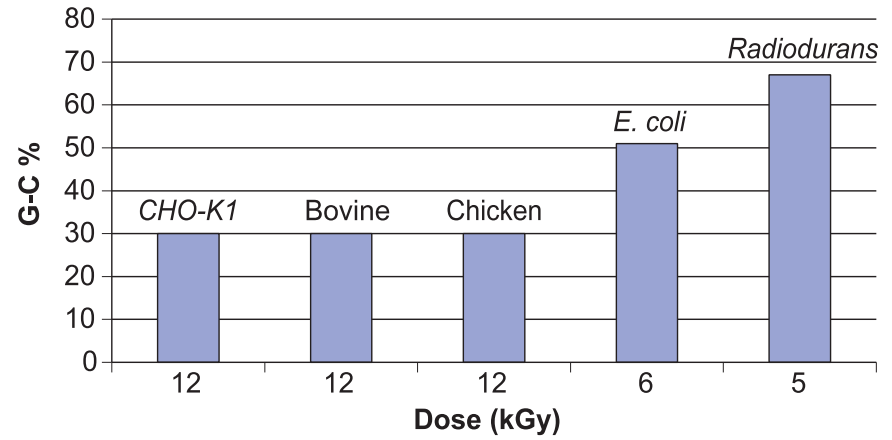

Figure 4. Guanine-cytosine ( $G-C)$ content (\%) vs. maximum dose of detection for measuring 8-hydroxydeoxyguanine (8-OHdG) in the DNA of irradiated samples.
Theoretically, the 8-OHdG production increases with the increase of GC content but larger production of the 8-OHdG from guanine base makes the native structure of DNA more fragile, and as the strands breakdown to smaller pieces, it might be washed out in the washing steps of ELISA. Large size DNA could bind to the polystyrene of ELISA plates strongly but small molecules produced by the radiation-induced oxidation could not bind strongly and might washed out from the plates. It is possible that the 8-OHdG produced could not bind to the monoclonal antibody, secondary antibody, substrate, etc. From this study it could be assume that the detection of gamma radiation-induced oxidation depends on the nature of DNA base composition and the detection of 8-OHdG could be considered as a potential method of detection of irradiated food.

\section{References}

1. Sonntag CV. 1987. The Chemical Basis of Radiation Biology, pp 1-35. Taylor \& Francis, London.

2. Sambrook J, Fritsch EF \& Maniatis T. 1989. Molecular Cloning - A Laboratory Manual, $2^{\text {nd }}$ edn. Cold Spring Harbor, New York.

3. Delincee H, Raffi JJ \& Belliardo JJ. 1991. Potential New Methods of Detection of Irradiated Food, p 5. Commission for European Communities, Brussels.

4. Steenken S. 1989. Purine bases, nucleosides and nucleotides: Aqueous solution redox chemistry and transformation reactions of their radical cations and $\mathrm{e}^{-}$and $\mathrm{OH}$ adducts. Chem Rev. 89: 503-520.

5. Ward JF. 1988. DNA damage produced by ionising radiation in mammalian cells: Identities, mechanism of formation and repairability. Prog Nucleic Acid Res Mol Biol. 35: 95-125.

6. Roots R \& Okada S. 1975. Estimation of life times and diffusion distances of radicals involved in x-ray-induced DNA strand breaks or killing of mammalian cells. Radiat Res. 64: 306-320.

7. Chapman JD, Reuvers AP, Borsa J \& Greenstock CL. 1973. Chemical radioprotection and radio sensitisation of mammalian cells growing in vitro. Radiat Res. 56: 291-306.

8. Helps CR \& Harbour DA. 1997. Comparison of the complete sequences of feline spumavirus with those of the primate spumaviruses reveals a short gag gene. J Gen Virol. 78: 2549-2564.

9. Rodens SM, Clark CL \& Spector DH. 1988. Separate DNA elements containing ATF/CREB and IE 86 binding sites differentially regulate the human cytomegalovirus UL112-113 promoter at early and late times in the infection. $J$ Virol. 72: 2697-2700.

10. Wei Q \& Fultz PN. 1988. Extensive diversification of human immunodeficiency virus type 1 subtype B strains during dual infection of a chimpanzee that progressed to AIDS. J Virol. 72: 3005-3008.

11. Voller A, Bidwell DE \& Barlett A. 1997. The enzyme-linked immunosorbant assay (ELISA): A Guide with Abstracts of Microplate Applications. Dynatech Laborotories Inc, Alexandria, Virginia.

12. Fleming JO \& Pen LB. 1988. Measurement of the concentration of murine IgG monoclonal antibody. J Immunol Methods. 107: 1-11.

13. Bruskov VI, Gaziew AI, Malakhova LV, Mantsygin YA \& Morenkov OS. 1996. Monoclonal antibodies to 8-oxo-2'-deoxyguanosine (8-hydroxyguanosine): Characterization and use in determining damage to DNA by reactive oxygen species. Biokhimiya. 61: 535-538.

14. Hirayama H, Tamaoka J \& Horikoshi K. 1996. Improved immobilization of DNA to microwell plates for DNA-DNA hybridisation. Nucleic Acids Res. 24: 4098-4102.

15. Dizdaroglu M. 1992. DNA base products formed in chromatin of gamma-irradiated cultured human cells. Mutation Res. 275: 331-342.

16. Blattner FR, Plunkett G, Bloch CA, Perna NT, Burland V \& Riley M. 1997. The complete genome sequence of Escherichia coli K-12. Science. 277: 1453-1462. 